advances in antiplatelet drugs, news in endovascular treatment of aortic diseases, conceptual approach to the venous malformation management, development and challenge of carotid artery stenting for carotid artery stenosis, approach to reperfusion therapy for acute ischemic stroke: mechanical thrombectomy, clinical challenges in chronic venous diseases, vicious circle of chronic venous diseases pathophysiology, an update on the management of DVT and post thrombotic syndrome, unusual arterial diseases, treatment for vena cava disease, arterial and venous thrombolysis diagnosis and treatment, venous thromboembolism, treatment of non-thrombotic iliac vein compression syndrome, EVAR complications, management of visceral arterial disease, Buerger's disease, lymphatic malformation and lymphedema, translational medicine, arterial science and innovation, vascular ultrasound, diabetic foot, stem cells and regenerative treatments, exercise in assessment and treatment of vascular diseases, wound repair.

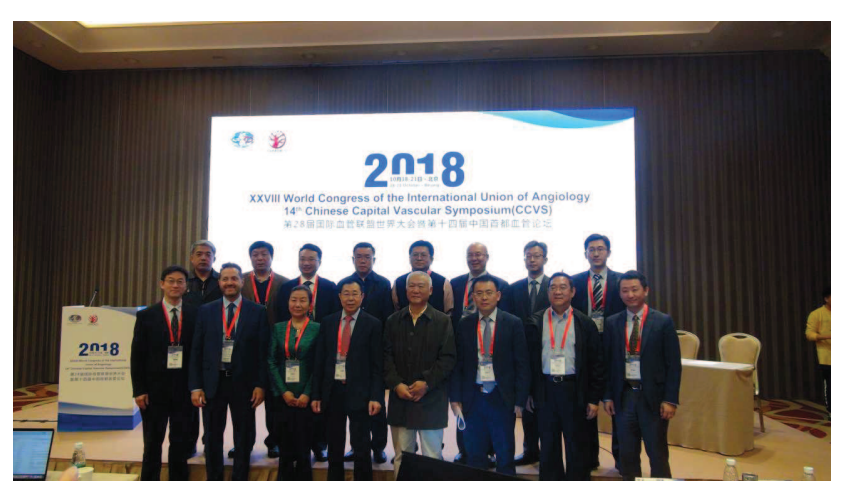

The Organizing Committee of the XXVIII IUA Meeting

\section{All-Russian scientific-practical conference with international participation. Nexus Medicus 2018: Modern approaches to rehabilitation}

Nov 9-10, 2018, Ulyanovsk, Russia

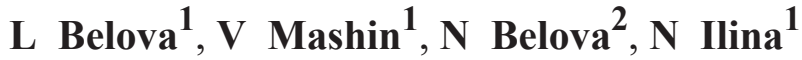

All-Russian scientific-practical conference with international participation "Nexus Medicus 2018: Modern
A lot of space was dedicated to Nursing and technicians.

This Congress was certainly a landmark in the development of the International Union of Angiology and the perfect illustration of its commitment as the "World Vascular Forum".

The organizing committee made a great scientific meeting as well as a unique cultural and human experience: a thorough scientific program with a distinguished faculty of international and Chinese experts, a convenient venue with all the needed facilities nearby the Olympic Stadium, and of course the thoughtful Chinese hospitality.

The next congress will be organized in Rome under the Presidency of Prof. PL Antignani, President elect of IUA.

Prof. Pierluigi Antignani

President elect

International Union of Angiology (IUA)

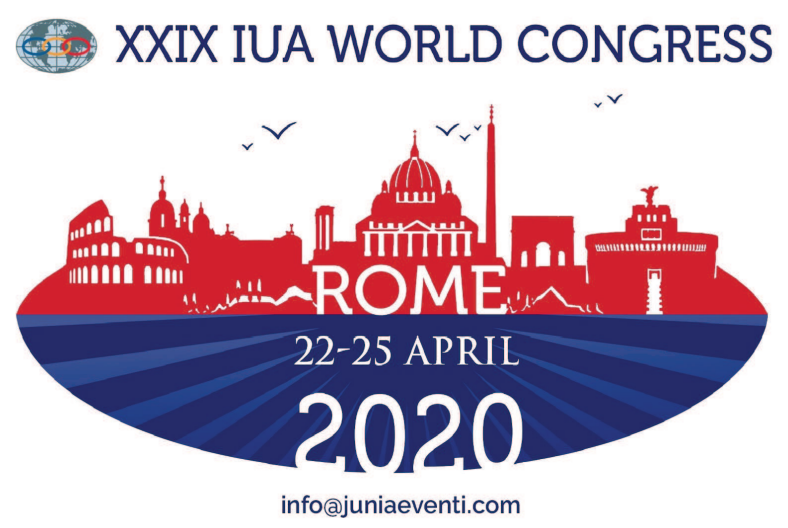

You are invited to join the XXIX IUA Meeting in Rome.

1 The Ulyanovsk State University, Ulyanovsk, Russia

2 The Research Centre of Neurology, Moscow, Russia submitted: Nov 19, 2018, accepted: Nov 19, 2018, EPub Ahead of Print: Dec 19, 2018, published: Jul 7, 2019 Conflict of interest: none

DOI: 10.24019/jtavr.56 - Corresponding author: Prof. Liudmila Belova, labelova@mail.ru

(C) 2018 Fondazione Vasculab impresa sociale ONLUS. All rights reserved.

approaches to rehabilitation" was held in Ulyanovsk on November 9-10, 2018. Over 1,211 medical specialists and 
512 young scientists from different cities of Russia took part in the event. Talks by leading scientists from Russia, Italy, Uzbekistan, United States were given.

The conference was organized by the Ulyanovsk State University, Union of Rehabilitologists of Russia, National Training Foundation, Federal Agency for Youth Affairs, Ministry of Health of the Ulyanovsk Region, Research Center of Neurology, Association of Clinical Phlebologists of the Ulyanovsk Region.

«Nexus Medicus» has been held since 2013 and gathers in Ulyanovsk scientists and doctors of various specialties from Russia, Italy, USA, Brazil, Argentina, Israel, to discuss issues of medicine. This year, the main topics of the conference were prospects for the development of medical rehabilitation in Russia and abroad, high-tech means of rehabilitation.

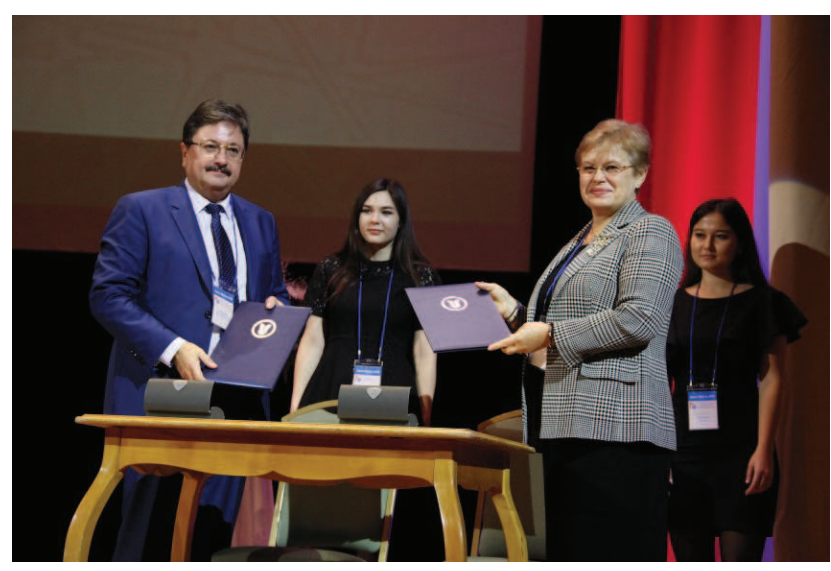

Agreement between the University of Ulyanovs, represented by the Chancellor, Prof Boris Kostishko and the Chief Specialist in Medical Rahabilitation of the Russian Federation, Prof Galina Ivanova.

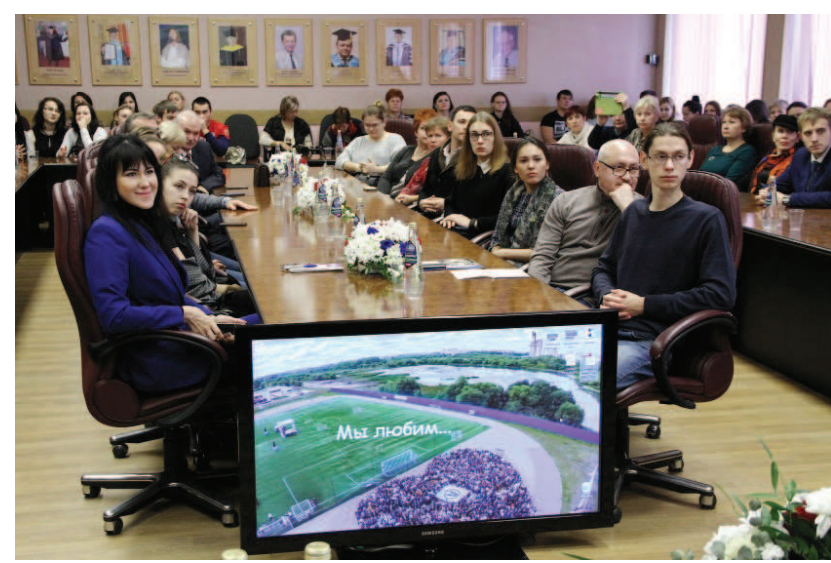

Youth session on "Building a socially significant project in the field of rehabilitation".

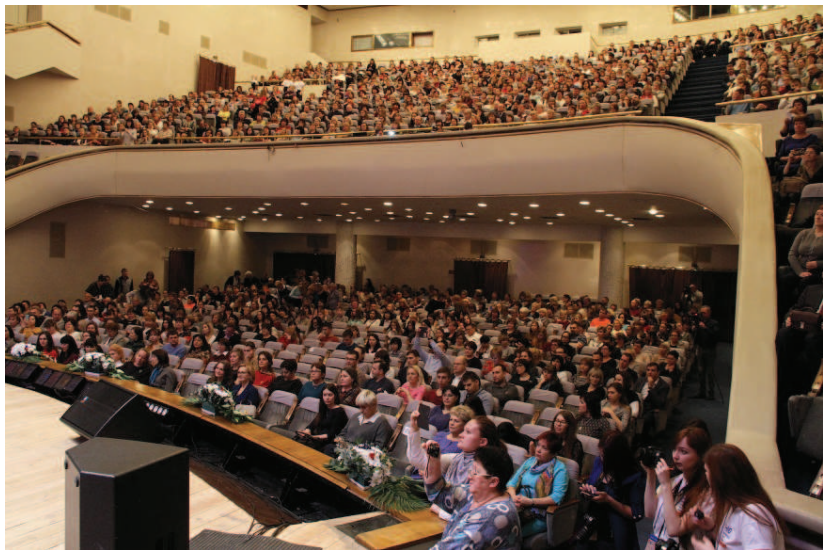

Opening the conference, the Chairman of the Government of the Ulyanovsk Region Alexander Smekalin noted that the discussion within the framework of Nexus Medicus of the issues of returning the affected economic independence and social usefulness is extremely important. It is full-fledged rehabilitation that contributes to reducing the number of people with disabilities and increasing the duration of the quality of life of the population.

Professor Boris Kostishko, the rector of the Ulyanovsk State University, welcomed the participants. He told about the history of "Nexus Medicus", that in five years the project has turned into a large-scale movement, consolidating the ideas of talented scientists from around the world. "It is particularly encouraging that students who have the opportunity to contribute to the development of the best practices of modern medicine participate in this movement on an equal footing with recognized scientists," said Boris Kostishko.

Professor Galina Ivanova, Chief Specialist in Medical Rehabilitation at the Ministry of Public Health of the Russian Federation, emphasized: "The purpose of such conferences is to build a medical rehabilitation system so that our citizens receive the maximum help based on the capabilities of national health care. Medical rehabilitation is a mandatory part of the provision of medical care to patients in any profile. A complete chain of care should work not only when the patient was rescued from death and operated on, but also to provide him with a high quality of life. This is not only rehabilitation, but also palliative care".

According to Sergey Panchenko, Minister of Health of the Ulyanovsk Region, "Nexus Medicus" attracts specialists from all over the world. "The subject matter of the conference is extremely relevant - rehabilitation helps to bring to life people with severe illness and received very active, sometimes even aggressive treatment. It is very important to conduct this work based on the best federal and international level."

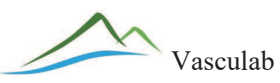


One of the brightest impressions of the conference was the presentation by Pier Luigi Antignani, Professor, Director of the Vascular Center Nuova Villa Claudia, Honorary President of the Italian Society for Vascular Investigation, President Elect of International Union of Angiology, with the reports: "The Consensus of the International Union of Phlebologists for the Rehabilitation of Patients with Chronic Venous Diseases of the Lower Limbs" and "Consensus of the International Union of Phlebologists on Congestive Pelvic Syndrome: what's new in treatment and rehabilitation?" and the master class "Ultrasound examination in chronic venous insufficiency of the lower limbs."

Doctors of various specialties dealing with the problems of venous pathology once again discussed the need for a systematic approach to patients with venous disorders and an individual approach to the development of an algorithm for rehabilitation measures for each group of patients, taking into account the severity of venous insufficiency, age, physical activity, associated diseases, mental health.

The conference participants had the opportunity to attend the round table "Principles of organizing rehabilitation help in Russia" and "Training specialists for a multidisciplinary rehabilitation team", a master class on "Positioning patients with focal brain lesions", a youth session "Forming a socially significant project in the field of rehabilitation", a poster session, a volunteer session.

The exhibition demonstrated to doctors modern medicines, physiotherapeutic devices and balneological equipment, advanced technical means of diagnostics and rehabilitation, auxiliary means for rehabilitation and care.

L Belova, V Mashin, N Belova, N Ilina 